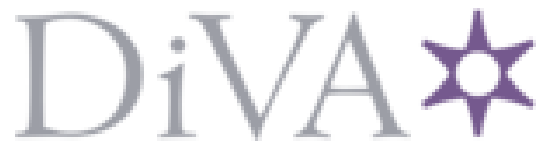

http://www.diva-portal.org

Preprint

This is the submitted version of a paper presented at The 8th International Conference on Information Intelligence Systems Applications 2017. Larnaca, Cyprus, August 27-30, 2017.

Citation for the original published paper:

Gudfinnsson, K., Strand, M. (2017)

Challenges with BI adoption in SMEs

In: Proceedings of the 8th International Conference on Information, Intelligence, Systems \& Applications (IISA) (pp. 172-177). IEEE https://doi.org/10.1109/IISA.2017.8316407

N.B. When citing this work, cite the original published paper.

Permanent link to this version:

http://urn.kb.se/resolve?urn=urn:nbn:se:his:diva-14976 


\section{Challenges with BI adoption in SMEs}

\author{
Kristens Gudfinnsson \\ School of Information Technology \\ University of Skövde \\ Skövde, Sweden \\ Kristens.Gudfinnsson@his.se
}

\author{
Mattias Strand \\ School of Engineering Science \\ University of Skövde \\ Skövde, Sweden \\ Mattias.Strand@his.se
}

\begin{abstract}
Business intelligence (BI) has become a well-known umbrella term both amongst academics and practitioners. Researchers have studied how companies can take advantage of BI and what challenges companies are facing when working with BI. However, research is mostly focused on large companies, despite the importance of small- and medium sized companies (SMEs) in both society and economically. This paper presents results of an in-depth qualitative case study on challenges faced by SMEs when adopting BI. The challenges are categorized according to a BI maturity model adopted as unit of assessment. The contribution of the results presented is two-folded; 1) It increases current literature regarding challenges when adopting BI in SMEs, and 2) It serves as guidance for SMEs on common pitfalls that ought to be avoided.
\end{abstract}

Keywords-Business Intelligence; Business Analytics; BI Maturity; BI Challenges; SMEs;

\section{INTRODUCTION}

Decision makers in companies are becoming more and more reliant on computer support and are using various decision support systems (DSS) to help them make better datadriven decisions [1], [2]. Business Intelligence (BI) is today a well-known umbrella term for IT-based decision support, covering various technological tools and organizational activities. The term can be found in literature dating back to the 1950's, when coined by Hans Peter Luhn [3], [4], and for the last two decades, BI has caught a huge interest by researchers, as well as practitioners.

In literature, BI has been defined in different ways and there is no consensus amongst researchers on a single definition. Moreover, BI may be considered as a content-free concept, since the meaning thereof may vary depending on whom is explaining the concept [5]. In addition, BI is also a cross discipline concept, ranging from strategic business insights to advanced technological aspects. For this work, the definition provided by Wixom \& Watson (2010) was used, stating that BI is: "a broad category of technologies, applications, and processes for gathering, storing, accessing, and analyzing data to help its user make better decisions" (Wixom \& Watson, 2010, p. 14). The definition encapsulates the broad category of IT solutions that may support BI initiatives in businesses, ranging from dedicated and highly advanced BI systems, via Enterprise Resource Planning (ERP) systems, to spreadsheet tools used for analytical purposes.

In literature, there are many examples on successful BI initiatives, although the degrees of success may be varying [6], [7]. Some true success stories are shown from the BI endeavors in Continental airlines [8] and Netflix [9] and [5] offers additional examples for inspiration. However, all these success stories include large companies. Research regarding how Small- and Medium sized Enterprises (SMEs ${ }^{1}$ ) use and implement BI has received limited attention in literature [10, $11,12]$. Some research has been published (e.g. [13, 14, 15]. In addition, [16] researched determinants and challenges to BI adoption in 20 polish SMEs. One of their findings was that the biggest challenges could be categorized as having business characters and organizational characters. One of the key organizational challenges was the lack of knowledge about BI systems and what they actually could contribute to the business [16]. Still, why advocating for the need to further investigate BI adoption in SMEs? There may be multiple reasons, but most importantly, SMEs are the backbone of e.g. Europe's economy and labor market and about $99 \%$ of all companies in Europe are categorized as SME companies [17]. Given the importance of SME companies in the world economy [14, 18] and the business opportunities provided by $\mathrm{BI}$, researchers need to increase current knowledge on BI adoption in general and the challenges faced by SMEs in particular. Existing research shows that SMEs are lagging behind larger companies [19, 20]. The research community needs to take the lead and understand why to be able to provide guidance that could aid SMEs to improve the adoption of BI and, in the long run, increasing their competitive edge. Such guidance requires an increased knowledge on current challenges and hinders. Only limited research has been done on challenges faced by SMEs when adopting BI and the need for more knowledge thereabout has been expressed by e.g. [14].

This paper aims at contributing to research by presenting challenges faced by SMEs when adopting BI. Within the scope

\footnotetext{
${ }^{1}$ According to the European Commission, small and medium sized companies have up to 250 employees.
} 
of an extensive case study towards four manufacturing SMEs, a BI maturity model was applied to measure how far these companies have come in their BI adoption initiatives. The BI maturity model thereby served as a means of structuring the analysis into different units of assessment. The categories provided in the maturity model are, in turn, based on previous research, but, as indicated above, primarily towards large companies. Therefore, SMEs may not have the same financial resources, skills or experience [16]. Furthermore, reaching the highest level of maturity according to the model might not be the ultimate goal for smaller companies.

The paper is structured as follows. Section II comprises the theoretical background. In Section III, the case study is presented. Section IV presents analysis and results. Finally, Section V concludes the paper, including ideas for future work.

\section{THEORETICAL BACKGROUND}

Research has shown that SMEs have been late adopters of $\mathrm{BI}$ and are lagging behind larger enterprises when it comes to utilizing the potential of BI [19], [20]. In a SME study in Thailand, [21] conducted 131 questionnaires and found most SMEs to be at the lowest maturity level when it comes to BI and that organizational culture was the main hindering factor when it came to BI adoption [21]. In alignment, in a survey towards 100 SMEs in South Africa, results showed that the companies were well aware of BI but lacked both resources and skills to successfully adopt BI [22].

Scholz et al. (2010) studied SMEs by using exploratory factor analysis (EFA) to identify the perception of BI benefits, challenges when introducing BI and factors that described the inner constitution and business behavior of the research subjects. The data collection method was done through an online questionnaire covering a wide range of BI related topics. Based on their results, Scholz et al. (2010) provide three general BI challenge factors for SMEs. These challenges are the following:

The first BI challenge factor depends on usage. This involved statements as that the systems are too complicated with complex processes when building BI reports. Furthermore, personnel competence was also raised as a challenge and a need for training was identified.

The second challenge depended on solution and data quality. This involved issues as software errors, insufficient support, inadequate security, contradictory data and performance problems.

The third challenge factor was challenges with interfaces. This factor contained problems as limited data export functionalities and conflation of data. This issue resulted in the need to manually import/export data which is more time consuming than an automatic process and may lead to data not being up-to-date.

In summary, three overall challenging factors were identified; (1) challenges depending on usage, (2) challenges depending on solution and data quality and (3) challenges with interfaces [14]. However, they do not provide any solution for how the SMEs can tackle the challenges they face in order to increase their maturity when it comes to adopting BI.

Olszak and Ziemba (2012) have investigated determinants and barriers when implementing BI in Polish SMEs. They found that the biggest challenges had two characteristics, they were either of business character or organizational character. The main business challenges were the lack of well-defined business problems that the BI initiative should address and not setting the expectations of the BI users. In addition, the lack of alignment between business and the BI system was considered a barrier in 9 out of 20 companies. When it came to organizational challenges, the largest barriers were found to be lack of manager's support and lack of knowledge about the capabilities of the BI system. Exceeding implementation budget and having ineffective BI project management were found to be challenges in three quarters of the companies and in thirteen cases the BI projects were described as complicated. Barriers involving users were also identified in the form of lack of user training and support (12 out of 20 companies) and user resistance was identified as a barrier in 11 companies. In addition, some technological barriers were identified i.e. lack of appropriate data and lack of flexibility in the BI system [16].

\section{BI Maturity models}

Maturity models for assessing organizational adoption of various e.g. tools, methods, and techniques has been around for decades. One of the earliest maturity models (1979) is Crosby's Quality Management Maturity Grid developed in the quality management field [26]. Since then, many novel maturity models have been introduced to help managers to e.g. reduce costs, create new products and increase competitiveness [24]. In general, maturity models are used to describe, explain and evaluate growth life cycles and to give organizations guidance on what areas to focus on to increase their maturity [25]. Most maturity models also share the property of having a number of dimensions and different stages illustrating maturity levels. Furthermore, maturity models can also be hierarchical (using sub-dimensions) and both one- or multi-dimensional [26, 27].

BI maturity models have been created both by researchers and practitioners and they usually contain similar components and follow the same structure as described above. Many BI maturity models have been developed by researchers, e.g. Enterprise Business Intelligence Maturity (EBIM) by Tan and Yeoh (2011), the Ladder of Business Intelligence (LOBI) by Cates and Gill (2005) and the Business Intelligence Development Model (BIDM) by Sacu and Spruit (2010). In addition, there are many companies that have created BI maturity models such as TERADATA's BI and data warehouse maturity model, Hewlett Packard Business Intelligence Maturity Model and SAS Information Evolution Model [28]. The maturity model (Figure 1) used in this research was developed by Lavalle et al. [29] and it is the results of a worldwide survey on BI analytics adoption, conducted in the fall of 2010 by MIT Sloan Management Review and IBM Institute for Business Value. The survey was answered by approximately 3000 executives, managers and analysts from more than 30 industries in 108 countries. 


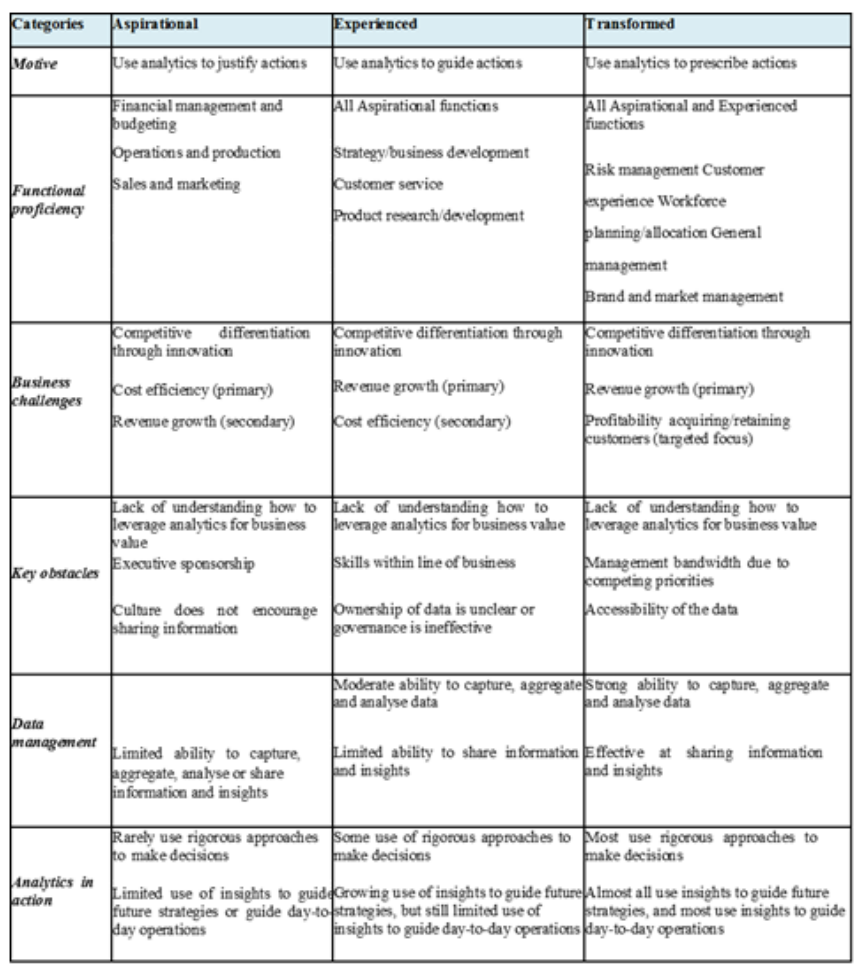

Figure 1: BI analytics maturity model (Lavalle et al. 2010)

The maturity model has six categories.

- Motive - the motive for using BI is analyzed.

- Functional proficiency - measures the ability to use BI within specific functions of the organization.

- Business challenges - highlights the main business challenges that BI is used to focus on.

- Key obstacles - focuses on obstacles of organizational character.

- Data management - measures the ability to capture, aggregate, analyze and share information and insights.

- Analytics in action - concerns how well a company applies analytics when making decisions.

The maturity model has three levels of maturity that may be reached. In addition, the model provides factors that must be fulfilled for being considered as progressed to the next level of the maturity model.

\section{THE CASE STUDY}

The research and results presented in this paper originate from an in-depth qualitative case study, complemented with the findings from an extensive literature review focusing on BI adoption in SMEs. The case study includes four SMEs and is an in-depth qualitative case study that complements earlier studies' questionnaires and interview surveys presented above.

The participating companies are all manufacturing companies and range from the lower end to the higher end of the SME category when it comes to number of employees with the smallest having around 50 employees and the largest close to 250 employees. Company A manufactures in-car accessories for mobile devices, selling their products on both the European and US market. Company A is family owned with about 120 employees. Company B manufactures screening equipment for industries worldwide and is owned by a large international enterprise group and has about 50 employees. Company C produces bookshelves as a subcontractor to a large Swedish furniture company, has close to 250 employees and is family owned. Company D mainly manufactures engines for marine applications, but also for power generators and off-road applications. The company is owned by a large international enterprise and has around 220 employees.

The material in the case study has been collected through semi-structured interviews, observations, and workshops. 60 interviews have been conducted, rather equally distributed between the four companies, covering business roles such as CEO, managers, group leaders and project managers. All interviews were recorded and transcribed. After transcription, each manuscript was analyzed and each challenge described by interviewees were coded within each category of the maturity model. The results of the interviews provided the foundation for understanding current practice and challenges faced by the SMEs within each category of the maturity model. The analysis helped to identify the challenges at the technological and organizational intersection as it focuses on how technology is used and what challenges the organization describes as obstacles for increased usage of BI.

\section{ANALYSIS AND RESULTS}

The analysis and results of the interviews are structured according to the six categories of the maturity model.

\section{Motive}

Motive looks at what the motives for using analytics are and if companies use analytics to prescribe actions, companies are considered to be a transformed business. The challenges raised in this category demonstrate how companies are more prone to look back at what has happened instead of trying to use BI to look forward and guide actions. For example, Company $\mathrm{C}$ said that sometimes they tried new material, e.g. new glue in the production without knowing much about how that would affect the production. After they had produced a bulk of products, they were able to see if they made the right call or not. The other companies described similar use with heavy focus on production planning. Company D said that when it comes to day-to-day operations, IT plays a limited role as a decision support but when it comes to more long-term strategic decisions they use data from various systems to get an overview of the current situation. The challenge, they described, is that they are trying to build a Lean production, but their IT systems are not designed based on Lean principles. That made it hard for them to use the IT support in a way that they wanted. When it comes to challenges in the motives category, two of the companies had limited knowledge on how BI analytics could be used to help guide actions while Companies $\mathrm{C}$ and $\mathrm{D}$ were trying to work with IT 
support and dashboards to help employees to better plan their work. Company $\mathrm{C}$ has a competent IT department that can do different analysis but there has been limited interest from the directors of the company. The biggest challenge for company D however is that their parent company has outsourced all IT support making it hard for them to influence how the IT solutions should be designed.

\section{Functional proficiency}

This category aims to assess which areas of the business that have managed to adopt BI analytics in their day-to-day operations. This category became quite interesting because two of the companies (company A and C) said that they didn't even bother to have budgets for their company. They only focused on production planning and making sure they were producing all the time. A possible reason for why they don't feel like working too much with budgets might be because they basically sell whatever they produce. Company $\mathrm{C}$ was very clear on this and said that the only goal they had was to produce as much as they possibly could. There were no production targets other than maximizing the production. The company directors had limited knowledge on how BI analytics could support the goal of maximizing production or aid when it comes to business strategy. In many of the interviews with Company C, the employees clearly stated that "we don't work with goals in this company". The biggest challenges for Company $\mathrm{C}$ were that employees working in the production line were not very good at registering correct information about why the production line stopped. This made it hard to do follow up on reasons for disruption in the production line.

Company A were not as blunt when it came to maximize production, in their view, the main issue is to have a good production plan and the rest will work itself out. Their main challenges were that the IT systems didn't support the type of follow-up that they felt they needed. They were clear on that many of their decisions were purely based on gut-feeling but they also understood the risk of relying so much on their gutfeeling. Companies' B and D used IT support to help with cost efficiency and revenue growth, but to a very different degree. Company B uses economic reports and budgets to large extent but do not use analytics to analyze the production, sales or to better understand their markets and customers. When asked about their challenges, they were clear on the fact that the users lacked skill to utilize their current systems in a more analytical way. One of the major issues raised was not knowing their market situation which gave way to uncertainty and a stressful environment. One of the interviewees said that they could only plan for the next two or three months because they had no idea on what customers would pop in or how the market actually looks like. The sales manager said he didn't monitor key performance indicators (KPIs), he only focused on project start dates. Company D had come a bit further than the other companies and were using BI for customer services and product research. In addition, business development and product development are closely linked. However, they had not implemented things like analyzing customer experience both because of lack of skill to do analysis and because of limited support to do that by the IT system. They acknowledged that they were quite immature when it came to utilize BI analytics and IT in general but they also said that overall they needed better IT support.

\section{Business challenges}

This category looks at how companies try to differentiate from competitors through innovation. All four companies were much more focused on cutting down costs compared to trying to find ways to increase revenue. However, as one interviewee said in Company D: "well, if we cut costs, we automatically increase our profits". This quote summarizes the strategy explained by all four companies, focus on being more efficient to get costs down and it will bring more profits. This further demonstrates the challenge of lack of knowledge on how BI can support companies to find new ways to increase revenue growth or to use analytics to guide actions.

\section{Key obstacles}

All companies described the challenge of understanding how to leverage analytics for business value. When asked about obstacles and challenges, they often said straight up "[...] well it's me, I have limited knowledge on how to use the information". In one of the companies, it became evident that executive sponsorship was lacking in many ways. The company has a tradition on how to conduct their business and that is "how it always has been done". The CEO asked similar questions on daily bases like how many packages they had produced or how many trucks they had shipped and after asking these questions for years, one of the IT staff created a simple dashboard that showed the answers to those standard questions.

The type of ownership appeared to play a role here because the two companies that were a part of a larger enterprise group described more pressure on using analytics and the executives were more open about using BI or IT in general to support decision making. Company B said that one of their challenges was that their owner was planning on implementing a new IT support but they didn't know when, stalling all their own efforts in increasing IT usage.

\section{Data management}

All four companies said they had data about almost everything. In general everything was in one system or the other according to the interviewees. However, when digging deeper into more specific parts of the manufacturing process, the interviewees started to highlight areas where data was completely missing. Company $\mathrm{C}$ described that there were so many possible errors when the production line stopped that they would be overflowed with information if they tried to analyze it all. What they were trying to do was to have the machine operators write in free-text what had gone wrong but that wasn't working out too well. They felt they were missing correct information at correct granularity level to be able to act on that information. One of the managers at Company $\mathrm{A}$ described that in fact their inventory balance was actually a complete chaos, making them very inefficient because they might be producing products that actually were to be found in a repository but the balance in the system said it didn't exist. 
Therefore, one of their major challenges was to actually have correct information on what products they had in storage.

\section{Analytics in action}

Overall the companies used analytics in a limited way if anything at all. Company A said that they hardly measure things and do not use budgets to any large extent or even KPIs. Company $\mathrm{C}$ doesn't use goals or budget and rely on their gut-feeling more than data when making decisions. The other companies were more forced into using KPIs and budgets because of their owner company put more pressure on them to do so and because it was used in other companies belonging to that owner. In one case, being forced to mainly focus on achieving a budget goal from the owner was a major challenge by itself. The limited amount of number analysis that was described in the interviews was heavily focused on the production process itself i.e. production planning and the amount of products produced. Future strategies were more based on experience and gut-feeling although they did use calculation programs (Excel) to analyze economic aspects of strategic decisions. However, that only came late in the strategic decision process so it cannot be said that analytics was used to gain new insights and opportunities, rather if used at all it was for basic economic calculations such as pay-off time.

\section{CONCLUSION}

The results support some of the previous findings in literature and adds new knowledge to current literature. The companies in this research are quite late adopters of BI, but the challenges and reasons for why they are late adopters is not as straight forward as for example in Nenchelele \& Pellissier (2014) who found lack of time, human resources, budgetary constraints and problems with creating awareness being the main challenges [23]. In addition, Scholz et al. (2010) had found three overall challenges that were (1) depending on usage, (2) depending on solution and data quality and (3) challenges with interfaces. In this research other areas have emerged. The type of company ownership seemed to play a large role when it came to making decision about IT support, if they were family owned or a part of a larger corporation. In addition, the companies were so focused on the production process itself that they expressed limited need in using IT in other areas. Identifying a need became an important aspect of this research because when the authors started to drill down into certain areas of the production (in three of the companies) a new need for data emerged from the company side and a new interest in using IT more for measurement and management started to emerge. In all three of the companies, they saw an opportunity to use IT as means to enforce a change in processes and added new KPIs to help making the effects of those changes transparent. This was quite a change for two of the companies that hardly used KPIs at all and had raised the point that they failed to see any value in focusing on KPIs. This could be related to lack of knowledge on how to use BI, but if the need is only to know how many packages you have produced during the day, motivating managers to increase BI usage when they have been making decisions and running their business for decades on gut-feeling is not an easy task.
Previous research has raised the challenge about not having the budget needed to implement BI according to needs [16, 23] but two out of four companies in this research described that they simply do not use budgets. It is quite unlikely that those are the only companies that decide to stop working with budgets (or never start) making this an interesting aspect to further look at. Both companies said that if they would see that an investment in better IT infrastructure would be needed, they would simply make that investment. Interestingly, during this research project, both companies started implementing new IT support that also provides the means to do more BI analytics. One of the fundamental challenges was failing to see in what areas and how IT could contribute to more efficient production and failing to see the value of KPIs. As pointed out by one of the interviewees from Company B: "it makes no sense to measure just because you want to measure”.

The main challenges are summarized in the following list:

- Current IT support did not fully support the manufacturing processes

- Limited interest from executives and owners on how to use BI as a decision support

- When IT is outsourced, the companies have difficulties getting the support needed

- Limited knowledge on how BI analytics can support production goals

- Difficulties getting data that requires manual input

- Lack of skills to use BI analytics in general

- Lack of KPIs, with focus on more company specific KPIs

- Lack of skills to see how BI can help increase revenue

- Type of ownership, family owned companies seemed less interested in using BI for decision support

- Risk of data overflow

- Having correct data

- Rely on gut-feeling rather than data

When looking at the challenges it becomes evident that they are related and touch upon different categories of the maturity model used for guidance. For example, the lack of interest from executives influences the motive to use BI for other purposes than looking into the review mirror. That in turn can influence the way different departments utilize BI. If departments within the organizations have primary focus on cutting costs and do that by looking back at what has happened in the past, changing the mindset to be more revenue focused and let BI guide actions can be hard. The lack of executive sponsorship becomes a key obstacle that influences all departments. However, as shown in this research, executive can be willing to sponsor BI initiatives but there is a lack of knowledge within the company of how to actually move on 
and elevate the use of BI. In one case, the company had difficulties making the changes they felt were needed because the IT department belonged to another organization.

\section{Future work}

More case studies need to be done in order to grasp the complexity of challenges faced by SMEs. Based on the findings from this work, the relationship between ownership and BI adoption may be analyzed further. In addition, this study concurs with previous studies and demonstrates that the companies need guidance supporting their BI adoption. Understanding their challenges is the first step. When it comes to SMEs, they seem to be dealing with different kind of challenges and therefore need different kind of tools, frameworks or models to support them. Finally, for being able to develop guidance, there is also a need for a more descriptive work covering the actual state-of-practice concerning BI adoption in SMEs in general. Such state-ofpractice may, for example, include detailed accounts concerning e.g. types of BI systems, business functions/units supported, types of users, challenges, critical success factors for adoption initiatives and data management.

\section{REFERENCES}

[1] P. Kumar, D. S. Chauhan, and V. K. Sehgal, "Selection of evolutionary approach based hybrid data mining algorithms for decision support systems and business intelligence," Proc. Int. Conf. Adv. Comput. Commun. Informatics - ICACCI '12, p. 1041, 2012.

[2] V.-H. Trieu, "Getting value from Business Intelligence systems: A review and research agenda," Decis. Support Syst., vol. 93, pp. 111-124, 2016.

[3] D. Agrawal, "The reality of real-time business intelligence," Lect. Notes Bus. Inf. Process., vol. 27 LNBIP, pp. 75-88, 2009.

[4] P. Wanda and S. Stian, "The Secret of my Success: An exploratory study of Business Intelligence management in the Norwegian Industry," Procedia Comput. Sci., vol. 64, no. 1877, pp. 240-247, 2015

[5] R. Sharda, D. Delen, and E. Turban, Business Intelligence and Analytics: Systems for Decision Support, Global 10t. Essex: Pearson Education Limited, 2014.

[6] P. Hawking, "Business Intelligence Excellence : A Company's Journey to Business Intelligence Maturity," Proc. 17th Am. Conf. Inf. Syst., pp. 1-9, 2011.

[7] C. M. Olszak, "Toward Better Understanding and Use of Business Intelligence in Organizations," Inf. Syst. Manag., vol. 33, no. 2, pp. 105123, 2016.

[8] R. Anderson-lehman, H. J. Watson, and B. H. Wixom, "C HAPTER 57 Flying High with Real-Time Business Intelligence Continental' s History," in Handbook on Decision Support Systems, Vol 2, Berlin: Springer-Verlag Berlin Heidelberg, 2008, pp. 443-462.

[9] J. Valacich and C. Schneider, Information Systems Today - Managing in the digital world., 4th ed. New Jersey: Pearson Education, 2010.

[10] W. Boonsiritomachai, M. McGrath, and S. Burgess, "A research framework for the adoption of Business Intelligence by Small and Medium-sized enterprises," Small Enterp. Assoc. Aust. New Zeal. (7th Annu. SEAANZ Conf. Proceedings), pp. 1-22, 2014.
[11] O. Grabova, J. Darmont, J.-H. Chauchat, and I. Zolotaryova, "Business Intelligence for Small and Middle-Sized Entreprises," ACM SIGMOD Rec., vol. 39, no. 2, pp. 39-50, 2010.

[12] N. N. M. Hatta, S. Miskon, N. M. Ali, N. S. Abdullah, N. Ahmad, H. Hashim, R. A. Alias, and M. A. Maarof, "Business intelligence system adoption theories in SMES: A literature review," ARPN J. Eng. Appl. Sci., vol. 10, no. 23, pp. 18165-18174, 2015.

[13] K. Gudfinnsson, M. Strand, and M. Berndtsson, "Analyzing business intelligence maturity,” J. Decis. Syst., vol. 24, no. 1, 2015.

[14] P. Scholz, C. Schieder, C. Kurze, P. Gluchowski, and M. Böhringer, "Benefits and Challenges of Business Intelligence Adoption in Small and Medium-Sized Enterprises," ECIS 2010 Proc., pp. 1-12, 2010.

[15] J. Darmont, B. Cedex, J. Chauchat, D. B. Feb, and L. Eric, "Business Intelligence for Small Middle-sized Enterprises," ACM SIGMOD Rec., vol. 39, pp. 39-50, 2011.

[16] C. Olszak and E. Ziemba, "Critical success factors for implementing business intelligence systems in small and medium enterprises on the example of upper Silesia, Poland," Interdiscip. J. Information, Knowl., vol. 7, 2012.

[17] A. Airaksinen, H. Luomaranta, P. Alajääskö, and A. Roodhuijzen, "Statistics on small and medium-sized enterprises," European Commission, 2015.2 [Online]. Available: http://ec.europa.eu/eurostat/statisticsexplained/index.php/Statistics_on_small_and_mediumsized_enterprises. [Accessed: 01-May-2017].

[18] L. Rovere, "Small and Medium-Sized Enterprises and IT Diffusion Policies in Europe," Small Bus. Econ., pp. 1-9, 1998.

[19] V. Voicu, D. Zirra, and D. Ciocirlan, "Business Intelligence Effective Sollutions of Management," Business, pp. 181-185, 2010.

[20] A. E. Baransel and C. Baransel, "Architecturing business intelligence for SMEs,” Proc. - Int. Comput. Softw. Appl. Conf., pp. 470-475, 2012.

[21] C. Srichai and N. Thammakoranonta, "Dimensions Influencing Business Intelligence Usage in Thailand SMEs," 2011, vol. 6, pp. 32-36.

[22] T. E. Nenzhelele, "Competitive Intelligence Location in Small and Medium-Sized Enterprises," Mediterr. J. Soc. Sci., vol. 5, no. 23, pp. 608-615, 2014.

[23] T. E. Nenzhelele and R. Pellissier, "Competitive Intelligence Implementation Challenges of Small and Medium-Sized Enterprises," Mediterr. J. Soc. Sci., vol. 5, no. 16, p. 92, 2014.

[24] T. Mettler, P. Rohner, and R. Winter, "Towards a Classification of Maturity Models in Information Systems," Manag. Interconnected World - ItAIS Ital. Assoc. Inf. Syst., no. April 2016, pp. 45-52, 2010.

[25] I. H. Rajterič, "Overview of business intelligence maturity models," Manag. J. Contemp. Manag. ..., vol. 15, pp. 47-67, 2010.

[26] P. Fraser, J. Moultrie, and M. Gregory, "The use of maturity models/grids as a tool in assessing product development capability," IEEE Int. Eng. Manag. Conf., vol. 1, pp. 244-249, 2002.

[27] G. Lahrmann and F. Marx, "Systematization of maturity model extensions," Lect. Notes Comput. Sci. (including Subser. Lect. Notes Artif. Intell. Lect. Notes Bioinformatics), vol. 6105 LNCS, pp. 522-525, 2010.

[28] A. Thamir and B. Theodoulidis, "Business Intelligence Maturity Models: Information Management Perspective," Inf. Softw. Technol. (Icist 2013), vol. 403, pp. 198-221, 2013.

[29] S. Lavalle, M. S. Hopkins, E. Lesser, R. Shockley, and N. Kruschwitz, "Analytics: The New Path to Value," MIT Sloan Manag. Rev., pp. 124, 2010.

[30] M. K. Sein, O. Henfridsson, M. Rossi, and R. Lindgren, “Action Design Research,” MIS Q., vol. 35, no. 1, pp. 37-56, 2011. 